\title{
Penerapan Augmented Reality pada Sistem Operasi Android untuk Pengenalan Profesi terhadap Anak Usia Dini
}

\author{
Irsyad Rabbani ${ }^{\mathrm{a} 1}$, Maria Rosaria Oktaviani ${ }^{\mathrm{a} 2}$, Muhammad Ilham Shobirin ${ }^{\mathrm{a} 3}$, Dolly Virgian Shaka Yudha \\ Sakti $^{\mathrm{a} 4}$ \\ aProgram Studi Teknik Informatika Universitas Budi Luhur Jl. Ciledug Raya No.99, RT.1/RW.2, Petukangan Utara, \\ Kec. Pesanggrahan, Kota Jakarta Selatan, Daerah Khusus Ibukota Jakarta 12260
}

${ }^{1} 1711501542$ astudent. budiluhur.ac.id
${ }^{2} 1711501005$ astudent. budiluhur.ac.id
${ }^{3} 1711502326$ astudent. budiluhur.ac.id
${ }^{4}$ dolly.virgianshaka@budiluhur.ac.id

\begin{abstract}
Abstrak
Anak-anak di usia dini sangatlah tertarik kepada hal yang baru, interaktif, memotivasi dan menyenangkan yang secara tidak langsung menjadi sistem pembelajaran bagi mereka. Untuk saat ini sistem pembelajaran yang tradisional seperti buku dan mainan kurang efektif dalam membuat anak tertarik untuk menggunakannya. Haruslah ada unsur teknologi di dalamnya sekaligus mampu mengenalkan fungsi dan kegunaan teknologi tersebut secara baik sejak anak masih di usia dini. Pengetahuan anak soal profesi yang bisa dijadikan cita-cita masih terbatas. Sedangkan saat ini macam-macam profesi ada banyak yang harus diketahui anak agar mereka memiliki wawasan yang lebih luas tentang dunia dan tahu bahwa bakat yang mereka punya sejak dini bisa menjadi profesi kelak. Augmented Reality merupakan teknologi yang memungkinkan sebuah objek maya atau virtual object dapat dilihat secara 3 dimensi dan seakan-akan ada di kenyataan. Dengan menentukan marker atau gambar nyata yang akan jadi target kamera smartphone, marker tersebut akan mengeluarkan bentuk 3 dimensi di layar smartphone jika kamera diarahkan ke marker. Penelitian ini dilakukan untuk mengetahui seberapa tertarik anak usia dini terhadap sistem pembelajaran secara digital. Dengan tujuan untuk mengedukasi anak usia dini dengan pembelajaran yang interaktif dan menarik dengan menggunakan smartphone. Metologi yang digunakan dalam penelitian ini adalah SDLC Waterfall. Penelitian ini dilakukan dengan tahapan wawancara dan uji coba aplikasi. Kami melakukan wawancara intens terhadap beberapa anak dengan usia dibawah 5 tahun sebagai acuan pemahaman tentang profesi. Dari hasil pengujian yang telah dilakukan, dapat disimpulkan bahwa aplikasi yang dibangun mampu menjadi media pembelajaran yang menyenangkan dan mampu menambah pengetahuan anak tentang profesi.
\end{abstract}

Kata kunci: Unity 3D, Augmented Reality, Marker Based Tracking, Vuforia, Android, Profesi.

\section{Augmented Reality on an Android Operating System to Introduce the Children About Professions}

\begin{abstract}
Children are interested in new things, interactive, motivate, and fun things that can be used for the learning system. Nowadays, the system of traditional learning such as books and toys are not effective to make children interest to use. Technology must be included in the learning system which is can be able to introduce the function and usefulness of the technology for children. Children's knowledge about the future of professions that can be used as their goal life is still limited. Meanwhile, there are kinds of professions that children must know with the result that they have more insight into the world and know what talent they have which is can become a profession in the future. Augmented Reality is a technology that makes virtual objects possible to be seen in 3 dimensions and as in reality. By determine marker or image that will be the target of a smartphone camera, that marker will result in a 3-dimensional shape on the smartphone screen if the camera was pointed at the marker. This research was
\end{abstract}


conducted to find out how Children were interested in the digital learning system. These research purposes are to educate children with interactive and interest learning using a smartphone. The methodology used in this research is an SDLC Waterfall. This research was conducted with interviews and application trials. We conducted intense interviews with several children under 5 years as a reference for understanding about profession.

Keywords: Unity 3D, Augmented Reality, Marker Based Tracking, Vuforia, Android, Profession.

\section{PENDAHULUAN}

Profesi adalah suatu pekerjaan seseorang yang dijalankan sesuai dengan keahliannya. Dalam mencapai keahlian ini seseorang harus memiliki keterampilan khusus. Seorang profesi memiliki keahlian pada bidang yang berbeda-beda seperti polisi, dokter, guru, dan sebagainya. Profesi sangat penting diajarkan pada anak usia dini agar mereka mampu mengenali profesi yang akan mereka pilih sebagai cita-citanya.

Pembelajaran profesi di Taman Kanak-Kanak lebih banyak memanfaatkan metode belajar dengan menggabungkan media visual dan menggunakan metode bercerita. Media visual hanya memberikan pembelajaran kepada anak berupa gambar- gambar yang tercetak pada buku atau lukisan.Metode bercerita hanya besifat searah hal itu membuat anak cepat bosan.Sehingga tidak dapat menangkap materi yang di sampaikan oleh tenaga pengajar.

Saat ini anak lebih memiliki ketertarikan tinggi terhadap teknologi multimedia, sehingga perlu memanfaatkan hal tersebut dalam memberikan media pembelajaran yang menarik perhatian anak dan bersifat interaktif [1].

Perkembangan teknologi informasi memungkinkan terciptanya sistem pembelajaran yang interaktif dan dan menarik sehingga membuat anak usia dini tidak mudah cepat bosan. Augmented Reality (AR) adalah salah satu media yang mendorong kegiatan pembelajaran menjadi lebih interaktif dan menarik. Augmented Reality (AR) merupakan cara alami untuk mengeksplorasi objek 3D dan data,AR merupakan suatu konsep perpaduan antara virtual reality dengan world reality. Sehingga objek-objek virtual 2 Dimensi (2D) atau 3 Dimensi (3D) seolah-olah terlihat nyata dan menyatu dengan dunia nyata. Pada teknologi AR, pengguna dapat melihat dunia nyata yang ada di sekelilingnya dengan penambahan obyek virtual yang dihasilkan oleh komputer [2].

Bedasarakan latar belakang yang telah diuraikan, maka di buatlah aplikasi Augmented Reality (AR) Pengenalan Profesi untuk anak usia dini dengan beranekaragam level dari bentuk pengenalan jenis-jenis pekerjaan yang dapat membantu anak-anak dalam menentukan cita-cita. Untuk membuat sebuah metode pembelajaran menggunakan Augmented Reality (AR) sebagai media penyampaian materi pembelajaran praktik langsung yang interaktif dan menarik. Metode pembelajaran lebih bermakna sebab anak secara langsung dapat mempelajari sehingga mampu diterapkan untuk menambah wawasan tentang profesi pada anak usia dini menggunakan smartphone android. Augmented Reality (AR) menawarkan hal yang berbeda dan lebih menarik dari buku ataupun pengenalan perkerjaan melalui lisan.

\section{Metodologi PenELITIAN}

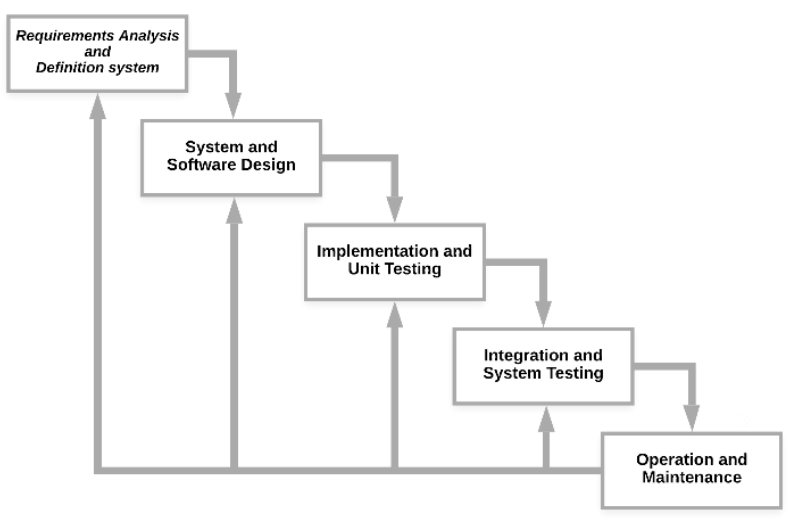

Gambar 1. SDLC waterfall

Untuk membuat aplikasi augmented reality pengenalan profesi menggunakan metode waterfall (Gambar 1).Model air terjun (Waterfall) adalah contoh dari proses dalam rencana driven prinsip, anda harus merencanakan dan menjadwalkan semua proses kegiatan sebelum mulai bekerja pada mereka pada tahapan utama dari model air terjun langsung mencerminkan kegiatan yang mendasar[3] :

1. Requirements Analysis and Definition system ini layanan, kendala, dan tujuan ditetapkan oleh konsultasi dengan pengguna sistem.Kemudian ditetapkan secara detail dan melayani sebagai spesifikasi sistem.

2. System and Software Design, proses desain sistem mengalokasikan membutuhkan perangkat keras atau perangkat lunak sistem dengan membentuk sistem secara keseluruhan rancangan. Desain perangkat lunak melibatkan identifikasi dan menggambarkan abstraksi sistem perangkat lunak.

3. Implementation and Unit Testing pada tahap ini desain perangkat lunak adalah sebagai seperangkat program atau unit program. Unit pengujian melibatkan verifikasi bahwa setiap unit memenuhi spesifikasinya.

4. Integration and System Testing, unit program individu atau program diintegrasikan dan diuji sebagai sistem yang lengkap untuk memastikan bahwa perangkat lunak persyaratan telah terpenuhi. Setelah pengujian sistem perangkat lunak disampaikan kepada pihak terkait. 
5. Operation and Maintenance, biasanya ( meskipun tidak selalu), ini adalah terpanjang fase siklus hidup. Sistem terinstal dan dimasukkan ke dalam penggunaan praktis.

\section{A. Rancangan Aplikasi}

Flowchart atau Bagan alir adalah bagan (chart) yang menunjukkan alir alir (flow) di dalam program atau prosedur sistem secara logika. Bagan alir (flowchart) yang digunakan terutama untuk alat alat bantu di komunikasi dan untuk dokumentasi[4]. Gambar 2 merupakan flowchart rancangan aplikasi dengan tahapan sebagai berikut :

1. Mulai membuka aplikasi dimana muncul splash screen dan halaman Menu Utama, di dalamnya terdapat empat button, yaitu button mulai, button panduan, button profil dan button keluar.

2. Button mulai saat di klik harus mengarahkan kamera pada marker untuk menampilkan objek, button kembali akan secara langsung tampil ketika button mulai pada menu utama di klik. ketika objek tampil secara langsung button audio,button panel narasi dan panel narasi akan tampil pada layar smartphone.



Gambar 2. Flowchart

\section{B. Augmented Reality}

Augmented Reality didefinisikan sebagai penggabungan objek atau komponen digital dengan objekobjek nyata yang ditampilkan dengan interaktif dan real time[5].

Dalam pembuatan aplikasi Augmented Reality beberapa perangkat yang diperlukan dalam pembuatan serta pengembangan aplikasi Augmented Reality adalah sebagai berikut :

1. Komputer. Komputer berfungsi sebagai perangkat yang digunakan untuk membuat semua proses yang akan terjadi dalam aplikasi. Kemudian untuk output aplikasi akan ditampilkan melalui layar smartphone.

2. Marker. Marker berfungsi sebagai gambar (image). .Dengan menggunakan marker ini maka pada saat aplikasi digunakan smartphone akan mengenali posisi dan orientasi dari marker dan akan memunculkan objek virtual yang berupa objek 3 dimensi.

3. Kamera Smartphone. Kamera Smartphone merupakan perangkat yang berfungsi sebagai recording sensor. Apabila kamera menangkap image yang mengandung marker, maka aplikasi akan mengenali marker tersebut.Lalu, Objek 3 dimensi akan muncul di layar smartphone dengan posisi objek berada di atas marker tersebut.

\section{Marker Based Tracking}

Marker based tracking adalah metode AR yang menggunakan marker atau penanda untuk memunculkan objek maya[6].Biasanya, menggunakan marker atau penanda objek dua dimensi yang memiliki suatu pola yang akan dibaca computer melalui media webcam atau kamera yang tersambung dengan komputer, biasanya merupakan ilustrasi hitam dan putih persegi dengan batas hitam tebal dan latar belakang putih[7].

\section{Unity $3 D$}

Unity $3 D$ adalah sebuah game engine yang berbasis cross-platform. Unity dapat digunakan untuk membuat sebuah game yang bisa digunakan pada perangkat komputer, ponsel pintar android, iPhone, PS3, dan bahkan $\mathrm{X}-\mathrm{BOX}[8]$. Unity menyediakan fitur pengembangan game dalam berbagai platform yaitu Web, Windows, Mac, Android, iOS, Xbox, Playstation 3 dan Wii. Unity mendukung pembuatan game $2 \mathrm{D}$ dan $3 \mathrm{D}$, namun lebih ditekankan pada 3D. Bahasa pemograman yang digunakan pada Unity yaitu Bahasa pemograman JaveScript, C\# dan BooScript[9].Unity 3D berfokus pada dua hasil grafik 2D dan 3D.Unity dikembangkan oleh Unity technologies.

\section{E. Vuforia}

Vuforia adalah Augmented Reality Software Development Kit (SDK) untuk perangkat mobile yang memungkinkan pembuatan aplikasi AR [8].Vuforia ini juga bisa di gabungkan dengan Unity dengan menggunakan Vuforia AR Extension for Unity yaitu dengan cara mendownload dari aplikasi unity 3D atau juga 
bisa mendownload dari website vuforia lalu meimportkan nya ke dalam aplikasi unity 3D. Agar dapat bekerja dengan baik, vuforia SDK memerlukan beberapa komponen penting. Komponen terebut antara lain kamera, image converter, tracker, video background render, application code, trackables, dan marker[10].

\section{F. Android}

Android adalah sistem operasi bersifat open source berbasis Linux dirancang untuk perangkat seluler layar sentuh seperti telepon pintar dan komputer tablet[11]. Awalnya, Google Inc membeli Android Inc ,pendatang baru yang membuat peranti lunak untuk ponsel. Kemudian untuk mengembangkan Android, dibentuklah Open Handset Alliance, konsorsium dari 34 perusahaan peranti keras, peranti lunak, dan telekomunikasi, termasuk Google, HTC, Intel, Motorola, Qualcomm, T- Mobile, dan Nvidia [12].

\section{G. Profesi}

Profesi merupakan kelompok lapangan kerja yang khusus melaksanakan kegiatan yang memerlukan ketrampilan dan keahlian tinggi guna memenuhi kebutuhan yang rumit dari manusia, di dalamnya pemakaian dengan cara yang benar akan ketrampilan dan keahlian tinggi, hanya dapat dicapai dengan dimilikinya penguasaan pengetahuan dengan ruang lingkup yang luas, mencakup sifat manusia, kecenderungan sejarah dan lingkungan hidupnya serta adanya disiplin etika yang dikembangkan dan diterapkan oleh kelompok anggota yang menyandang profesi tersebut[13].

\section{H. Black Box}

Black-Box Testing merupakan pengujian yang berfokus pada spesifikasi fungsional dari perangkat lunak, tester dapat mendefinisikan kumpulan kondisi input dan melakukan pengetesan pada spesifikasi fungsional program[14].Pada aplikasi augmented reality pengenalan profesi, metode uji di terapkan untuk menguji unit testing, integration testing, functional testing dan acceptance testing . Pengujian black box di tujukan untuk pengujian eksternal sistem dimana pengujian melibatkan stakeholder untuk mengetahui apakah masukan dan luaran sesuai dengan hasil yang diharapkan[15].

\section{HASIL DAN PEMBAHASAN}

\section{A. Pembuatan Aplikasi Augmented Reality}

Dalam pembuatan Aplikasi yang memuat informasi seputar macam-macam profesi ini penulis melakukan beberapa persiapan diantaranya:

1. Menentukan macam-macam profesi yang akan dijadikan materi berdasarkan profesi yang masih belum dikenal, sudah dikenal namun belum secara mendalam ataupun yang masih salah dimengerti oleh anak. Karena ada banyak sekali profesi di dunia maka dipilih 10 profesi untuk ditampilkan dalam aplikasi ini.
2. Membuat teks narasi untuk menambah informasi yang dapat diperoleh anak-anak. Teks Narasi berisi tentang penjelasan profesi dengan katakata yang mudah dipahami dan membuat tertarik terhadap profesi tersebut. Teks ini juga bisa dijadikan media belajar membaca anak.

3. Merekam suara dari teks narasi untuk menambah pilihan cara informasi yang bisa didapat. Suara ini diambil dari sudut pandang orang pertama, sehingga seolah-olah karakter 3D yang tampil di dalam aplikasi lah yang berbicara.

4. Pembuatan gambar marker. Hal yang penting di dalam aplikasi Augmented Reality dengan metode Marker Based Tracking adalah marker. Maka penulis harus menentukan desain gambar dari marker sejumlah profesi yang akan ditampilkan.

Adapun perangkat yang dibutuhkan untuk membuat aplikasi ini terdiri dari perangkat keras (hardware) dan perangkat lunak (software). Yang dapat dilihat pada tabel I dan tabel II.

TABEL I

SPESIFIKASI PERANGKAT KERAS

\begin{tabular}{|l|l|}
\hline \multicolumn{1}{|c|}{ Perangkat } & \multicolumn{1}{c|}{ Spesifikasi } \\
\hline Processor & Intel Core i3 $8145 \mathrm{U} 2.1 \mathrm{GHz}$ \\
\hline RAM & $4 \mathrm{~GB}$ \\
\hline Harddisk & $512 \mathrm{~GB}$ \\
\hline
\end{tabular}

TABEL II

SPESIFIKASI PERANGKAT LUNAK

\begin{tabular}{|c|l|}
\hline \multicolumn{1}{|c|}{ Perangkat } & \multicolumn{1}{c|}{ Penggunaan } \\
\hline Unity 3D 2017.4.11f1 (64-bit) & $\begin{array}{l}\text { Digunakan untuk membuat } \\
\text { aplikasi AR. }\end{array}$ \\
\hline Microsoft Visio 2016 (64-bit) & $\begin{array}{l}\text { Digunakan untuk } \\
\text { menggambarkan flowchart dari } \\
\text { aplikasi. }\end{array}$ \\
\hline Adobe Photoshop CS6 (64-bit) & $\begin{array}{l}\text { Digunakan untuk membuat } \\
\text { marker AR, desain menu aplikasi } \\
\text { dan ikon aplikasi. }\end{array}$ \\
\hline
\end{tabular}

\section{B. Hasil implementasi aplikasi pada smartphone} android

Berikut akan ditampilkan hasil pengujian paling presisi dari aplikasi Pengenalan Profesi:

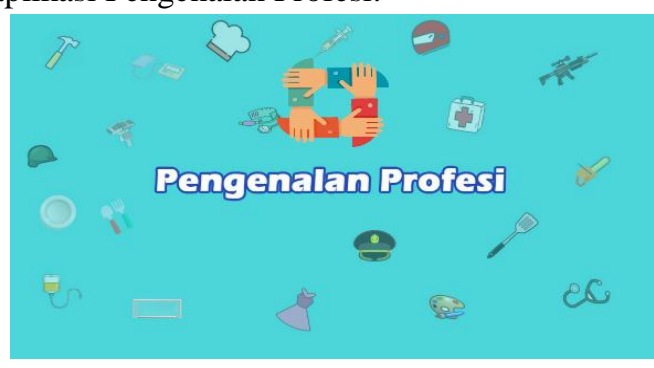

Gambar 3. Tampilan splash screen 
Gambar 3 merupakan tampilan splash screen dari aplikasi Pengenalan Profesi.

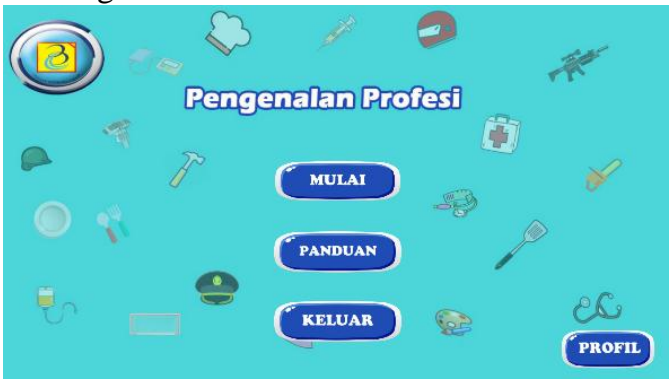

Gambar 4. Tampilan menu utama

Gambar 4 merupakan tampilan menu utama dari aplikasi Pengenalan Profesi.

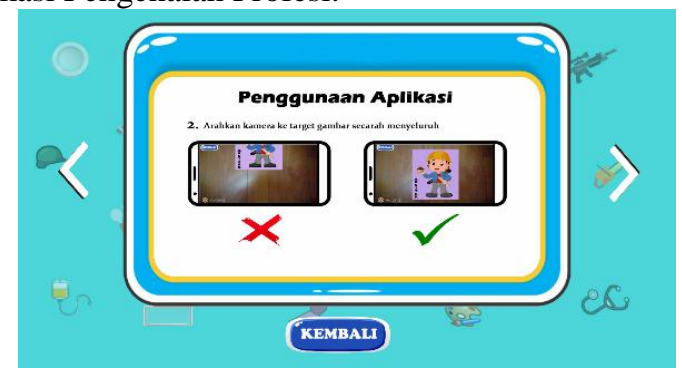

Gambar 5. Tampilan panduan penggunaan aplikasi

Gambar 5 merupakan tampilan panduan cara menggunakan aplikasi Pengenalan Profesi.

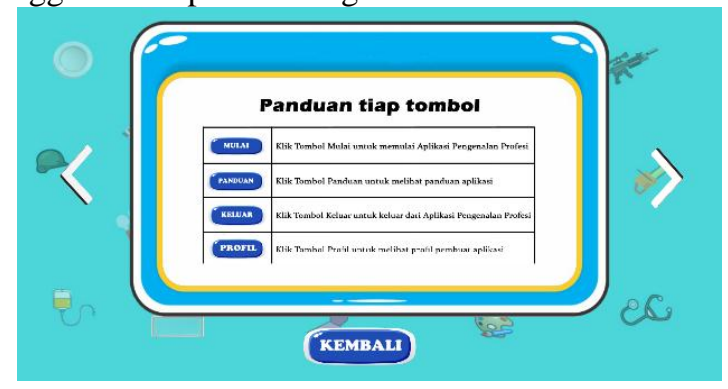

Gambar 6. Tampilan panduan tiap tombol

Gambar 6 merupakan tampilan panduan fungsi tiap tombol di dalam aplikasi Pengenalan Profesi.

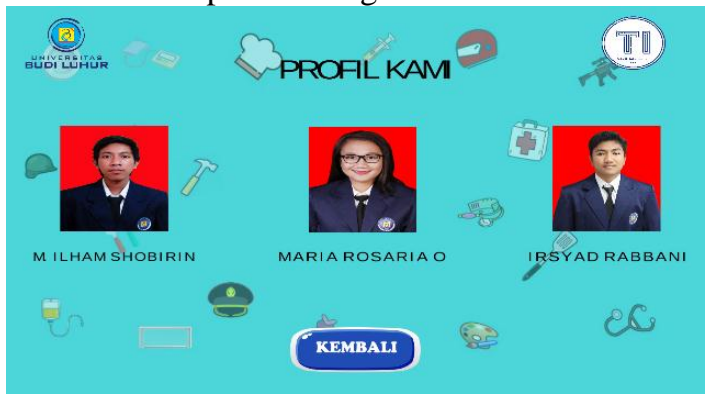

Gambar 7. Tampilan halaman profil

Gambar 7 merupakan tampilan halaman profil dari pembuat aplikasi Pengenalan Profesi.

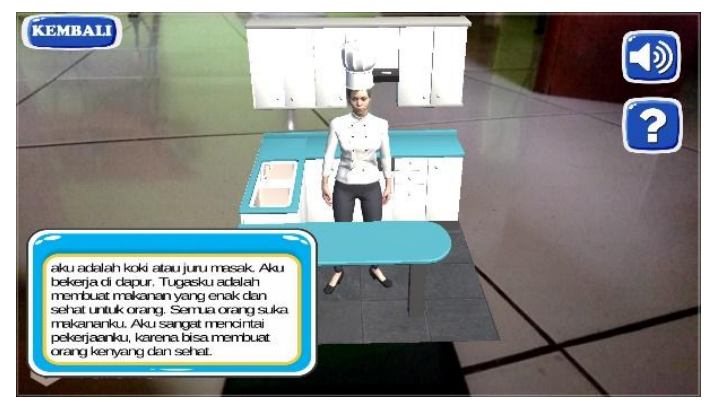

Gambar 8. Tampilan objek dan UI

Gambar 8 merupakan tampilan menu AR yang menampilkan objek 3D, suara narasi, dan teks penjelasan berdasarkan objek yang muncul.

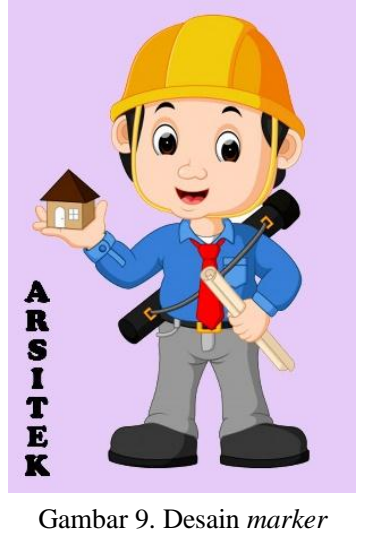

Gambar 9 merupakan tampilan desain dari target marker yang dipakai.

\section{Pengujian}

Pada tahap pengujian dilakukan pengujian Kompatibilas, UAT \& Usability. Pengujian tersebut dilakukan untuk mengetahui tanggapan responden atau user terhadap aplikasi dan menentukan apakah aplikasi Pengenalan Profesi sudah sesuai dengan tujuan awal pembuatan aplikasi.

\section{1) Pengujian Kompatibilitas: Pengujian} Kompatibilitas dilakukan dengan memasang dan menjalankan aplikasi ke dalam beberapa perangkat android yang berbeda dengan tujuan mengetahui tingkat keberhasilan aplikasi saat berjalan di setiap perangkat tersebut. Pada Tabel III, memperlihatkan hasil pengujian pada 10 perangkat android.

TABEL III

PENGUJian Kompatibilitas SMARTPHONE

\begin{tabular}{|c|c|c|c|}
\hline No & $\begin{array}{c}\text { Merek } \\
\text { Perangkat }\end{array}$ & \multicolumn{1}{|c|}{ Spesifikasi } & Keterangan \\
\hline & & - OS: Android 6.0 & \\
& & (Marshmallow) & $\begin{array}{c}\text { Aplikasi berjalan } \\
\text { lancar, tampilan } \\
\text { aplikasi full }\end{array}$ \\
1 & $\begin{array}{c}\text { Xiaomi Redmi } \\
\text { Note 4 }\end{array}$ & $\begin{array}{l}\text { - Kamera: } 13 \mathrm{MP} \\
\text { - Layar: } 1080 \times \text { 920 } \\
\text { pixels, } 5.5 \text { inches }\end{array}$ & \\
\hline
\end{tabular}




\begin{tabular}{|c|c|c|c|}
\hline 2 & $\begin{array}{l}\text { Xiaomi Redmi } \\
\text { S2 }\end{array}$ & $\begin{array}{l}\text { - OS: Android } 8.1 \\
\text { (Oreo) } \\
\text { - Kamera: } 12 \mathrm{MP} \\
\quad \& 5 \mathrm{MP} \\
\text { - Layar: } 720 \times 1440 \\
\text { pixels, } 5.99 \text { inches } \\
\end{array}$ & $\begin{array}{c}\text { Aplikasi berjalan } \\
\text { lancar, tampilan } \\
\text { aplikasi tidak full }\end{array}$ \\
\hline 3 & Sony Xperia XZ & 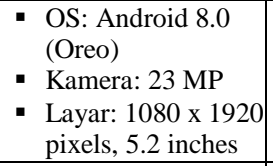 & $\begin{array}{c}\text { Aplikasi berjalan } \\
\text { lancar, tampilan } \\
\text { aplikasi full }\end{array}$ \\
\hline 4 & $\begin{array}{l}\text { Xiaomi Redmi } \\
\text { Note } 5\end{array}$ & $\begin{array}{l}\text { - OS: Android } 7.1 \\
\text { (Nougat) } \\
\text { - Kamera: } 12 \mathrm{MP} \& \\
5 \text { MP } \\
\text { - Layar: } 720 \mathrm{x} \\
1440 \text { pixels, } 5.99 \\
\text { inches }\end{array}$ & $\begin{array}{l}\text { Aplikasi berjalan } \\
\text { lancar, tampilan } \\
\text { aplikasi tidak full }\end{array}$ \\
\hline 5 & $\begin{array}{c}\text { Samsung Galaxy } \\
\text { A20 }\end{array}$ & $\begin{array}{l}\text { - OS: Android } 9.0 \\
\text { (Pie) } \\
\text { - } \text { Kamera: } 13 \text { MP \& } \\
\text { 5MP } \\
\text { - Layar: } 720 \text { x } 1560 \\
\text { pixels, } 6.4 \text { inches }\end{array}$ & $\begin{array}{l}\text { Aplikasi berjalan } \\
\text { lancar, tampilan } \\
\text { aplikasi tidak full }\end{array}$ \\
\hline 6 & $\begin{array}{c}\text { Samsung Galaxy } \\
\text { A3 }\end{array}$ & $\begin{array}{l}\text { - OS: Android 6.0.1 } \\
\text { (Marshmallow) } \\
\text { - Kamera: } 13 \mathrm{MP} \\
\text { - Layar: } 720 \text { x } 1280 \\
\text { pixels, } 4.7 \text { inches }\end{array}$ & $\begin{array}{l}\text { Aplikasi berjalan } \\
\text { lancar, tampilan } \\
\text { aplikasi tidak full }\end{array}$ \\
\hline 7 & $\begin{array}{c}\text { Xiaomi Mi A2 } \\
\text { Lite }\end{array}$ & $\begin{array}{l}\text { - OS: Android } 8.1 \\
\text { (Oreo) } \\
\text { - } \text { Kamera: } 12 \mathrm{MP} \& \\
5 \mathrm{MP} \\
\text { - Layar: } 1080 \text { x } 2280 \\
\text { pixels, } 5.84 \text { inches }\end{array}$ & $\begin{array}{l}\text { Aplikasi berjalan } \\
\text { lancar, tampilan } \\
\text { aplikasi tidak full }\end{array}$ \\
\hline 8 & $\begin{array}{l}\text { Xiaomi Redmi } \\
\text { Note } 7\end{array}$ & 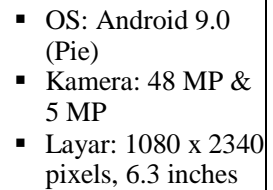 & $\begin{array}{l}\text { Aplikasi berjalan } \\
\text { lancar, tampilan } \\
\text { aplikasi tidak full }\end{array}$ \\
\hline 9 & $\begin{array}{l}\text { Xiaomi Redmi } \\
\text { Note } 8\end{array}$ & 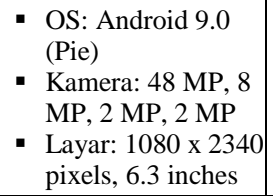 & $\begin{array}{l}\text { Aplikasi berjalan } \\
\text { lancar, tampilan } \\
\text { aplikasi tidak full }\end{array}$ \\
\hline 10 & Xiaomi Redmi 5 & 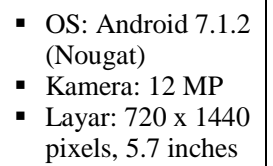 & $\begin{array}{l}\text { Aplikasi berjalan } \\
\text { lancar, tampilan } \\
\text { aplikasi tidak full }\end{array}$ \\
\hline
\end{tabular}

Hasil pengujian menunjukkan bahwa aplikasi dapat berjalan lancar di semua perangkat android dengan versi sistem operasi mulai dari 6.0 (Marshmallow) hingga 9.0 (Pie).

Kemudian dilakukan juga pengujian terhadap jarak agar diketahui jarak dimana objek 3D akan terdeteksi dan terlihat pada smartphone yang ditunjukkan pada tabel IV.
TABEL IV

PENGUJIAN JARAK TERHADAP OBJEK 3D

\begin{tabular}{|c|c|c|}
\hline \multirow{2}{*}{ Jarak } & \multicolumn{2}{|c|}{ Objek 3D } \\
\cline { 2 - 3 } & Terdeteksi di Awal & Terlihat \\
\hline $10 \mathrm{~cm}$ & YA & YA \\
\hline $20 \mathrm{~cm}$ & YA & YA \\
\hline $40 \mathrm{~cm}$ & YA & YA \\
\hline $60 \mathrm{~cm}$ & TIDAK & YA \\
\hline $80 \mathrm{~cm}$ & TIDAK & YA \\
\hline $100 \mathrm{~cm}$ & TIDAK & YA \\
\hline
\end{tabular}

2) Pengujian UAT: Pengujian UAT (User Acceptance Test) dilakukan dengan mengajukan sejumlah pertanyaan (kuisioner) terhadap 20 responden/pengguna aplikasi dengan kisaran umur 5-6 tahun. Pengujian UAT terdiri atas 12 pertanyaan dan setiap pertanyaan diberi pilihan jawaban YA atau TIDAK/RAGU.

TABEL V

HASIL PENGUJIAN UAT

\begin{tabular}{|c|c|c|c|c|}
\hline \multirow[b]{2}{*}{ No. } & \multirow{2}{*}{$\begin{array}{l}\text { Elemen } \\
\text { Observasi }\end{array}$} & \multicolumn{2}{|c|}{ Tanggapan } & \multirow{2}{*}{$\begin{array}{c}\text { Presentase } \\
\text { Likert }\end{array}$} \\
\hline & & YA & TIDAK & \\
\hline \multicolumn{5}{|c|}{ Aspek Informasi yang Diberikan } \\
\hline 1 & $\begin{array}{l}\text { Apakah setiap } \\
\text { menu yang ada } \\
\text { pada aplikasi } \\
\text { bermanfaat } \\
\text { dengan baik? }\end{array}$ & 16 & 4 & $80 \%$ \\
\hline 2 & $\begin{array}{l}\text { Apakah kamu } \\
\text { dapat menerima } \\
\text { informasi yang } \\
\text { disampaikan di } \\
\text { dalam aplikasi } \\
\text { dengan baik? }\end{array}$ & 18 & 2 & $90 \%$ \\
\hline 3 & $\begin{array}{l}\text { Apakah kamu } \\
\text { dapat memahami } \\
\text { isi informasi pada } \\
\text { panduan? }\end{array}$ & 16 & 4 & $80 \%$ \\
\hline \multicolumn{5}{|c|}{ Aspek Tampilan Aplikasi } \\
\hline 4 & $\begin{array}{l}\text { Apakah kamu } \\
\text { dapat mengenali } \\
\text { objek yang ada } \\
\text { pada aplikasi } \\
\text { Pengenalan } \\
\text { Profesi? }\end{array}$ & 17 & 3 & $75 \%$ \\
\hline 5 & $\begin{array}{l}\text { Apakah audio } \\
\text { narasi pada } \\
\text { aplikasi } \\
\text { Pengenalan } \\
\text { Profesi terdengar } \\
\text { jelas? }\end{array}$ & 19 & 1 & $95 \%$ \\
\hline
\end{tabular}




\begin{tabular}{|c|l|c|c|c|}
\hline 6 & $\begin{array}{l}\text { Apakah teks narasi } \\
\text { yang tampil pada } \\
\text { aplikasi dapat terbaca } \\
\text { dengan jelas? }\end{array}$ & 16 & 4 & $80 \%$ \\
\hline 7 & $\begin{array}{l}\text { Apakah warna tulisan } \\
\text { dan gambar latar } \\
\text { belakang terlihat jelas? }\end{array}$ & 20 & 0 & $100 \%$ \\
\hline \multicolumn{5}{|c|}{ Aspek Ketertarikan menggunakan Aplikasi } \\
\hline 8 & $\begin{array}{l}\text { Apakah objek pada } \\
\text { aplikasi membuatmu } \\
\text { tertarik? }\end{array}$ & 19 & 1 & $95 \%$ \\
\hline 9 & $\begin{array}{l}\text { Apakah aplikasi AR } \\
\text { Pengenalan Profesi } \\
\text { mudah digunakan? }\end{array}$ & 17 & 3 & $75 \%$ \\
\hline 10 & $\begin{array}{l}\text { Apakah aplikasi } \\
\text { Pengenalan Profesi ini } \\
\text { menyenangkan? }\end{array}$ & 20 & 0 & $100 \%$ \\
\hline \multicolumn{5}{|c|}{ Total Persentase } \\
\hline
\end{tabular}

3) Pengujian usability: Pengujian usability dilakukan dengan mengamati reaksi sejumlah 20 responden atau pengguna saat menggunakan aplikasi dengan kisaran umur 5-6 tahun. Terdapat 12 pertanyaan yang diajukan, setiap pertanyaan tersebut dijawab dengan Likert Scale yaitu Sangat Baik (SB), Baik (B), Kurang (K), Sangat Kurang (SK). Hasil pengujian ini dapat dilihat pada tabel VI berikut.

TABEL VI

Hasil Pengujian Usability

\begin{tabular}{|c|c|c|c|c|c|c|}
\hline \multirow[b]{2}{*}{ No. } & \multirow[b]{2}{*}{ Elemen Observasi } & \multicolumn{4}{|c|}{ Tanggapan } & \multirow{2}{*}{$\begin{array}{c}\text { Persentas } \\
\text { e Likert }\end{array}$} \\
\hline & & $\begin{array}{l}\mathbf{S} \\
\mathbf{B}\end{array}$ & $\mathbf{B}$ & $\mathbf{K}$ & $\begin{array}{l}\mathbf{S} \\
\mathbf{K}\end{array}$ & \\
\hline 1 & $\begin{array}{l}\text { Anak dapat } \\
\text { mengarahkan kamera } \\
\text { ke marker dengan } \\
\text { benar }\end{array}$ & 17 & 3 & & & $85 \%$ \\
\hline 2 & $\begin{array}{l}\text { Anak dapat wawasan } \\
\text { baru tentang profesi }\end{array}$ & 19 & 1 & & & $95 \%$ \\
\hline 3 & $\begin{array}{l}\text { Anak dapat menerima } \\
\text { informasi yang } \\
\text { disampaikan }\end{array}$ & 18 & 2 & & & $90 \%$ \\
\hline 4 & $\begin{array}{l}\text { Anak dapat } \\
\text { menggunakan aplikasi } \\
\text { tanpa bantuan }\end{array}$ & 16 & 4 & & & $80 \%$ \\
\hline 5 & $\begin{array}{l}\text { Anak dapat } \\
\text { mengetahui tujuan dari } \\
\text { setiap profesi yang } \\
\text { ditampilkan }\end{array}$ & 18 & 2 & & & $90 \%$ \\
\hline 6 & $\begin{array}{l}\text { Anak dapat memiliki } \\
\text { cita-cita dan } \\
\text { penjelasan lengkap } \\
\text { tentang cita-citanya }\end{array}$ & 18 & 2 & & & $90 \%$ \\
\hline 7 & $\begin{array}{l}\text { Anak dapat keluar dari } \\
\text { aplikasi dengan mudah }\end{array}$ & 17 & 3 & & & $85 \%$ \\
\hline 8 & $\begin{array}{l}\text { Anak dapat melihat } \\
\text { tiap tombol dengan } \\
\text { mudah }\end{array}$ & 20 & 0 & & & $100 \%$ \\
\hline 9 & $\begin{array}{l}\text { Anak dapat membuat } \\
\text { suara pada objek } \\
\text { keluar dengan mudah }\end{array}$ & 17 & 3 & & & $75 \%$ \\
\hline 10 & $\begin{array}{l}\text { Anak dapat } \\
\text { menggunakan tombol } \\
\text { panel informasi } \\
\text { dengan mudah }\end{array}$ & 17 & 3 & & & $70 \%$ \\
\hline \multicolumn{6}{|c|}{ Total Persentase } & $88.5 \%$ \\
\hline
\end{tabular}


VALUE ANALYSIS (Studi Kasus: Aplikasi website praktekdokter)," J. SAINSTECH Politek. Indonusa Surakarta, vol. 5, no. 2, pp. 52-57, 2018.

[15] D. W. Utomo, D. Kurniawan, and Y. P. Astuti, "Teknik Pengujian Perangkat Lunak Dalam Evaluasi Sistem Layanan Mandiri Pemantauan Haji Pada Kementerian Agama Provinsi Jawa Tengah," Simetris J. Tek. Mesin, Elektro dan Ilmu Komput., vol. 9 , no. 2, pp. 731-746, 2018. 